\title{
Landslide monitoring with interferometric SAR in Liugui, a vegetated area
}

\author{
Peter Tian-Yuan Shih *, Huijung Wang, Kuo-Wei Li, Jyh-Jong Liao, and Yii-Wen Pan \\ Disaster Prevention and Water Environment Research Center, National Chiao Tung University, Hsinchu City, Taiwan
}

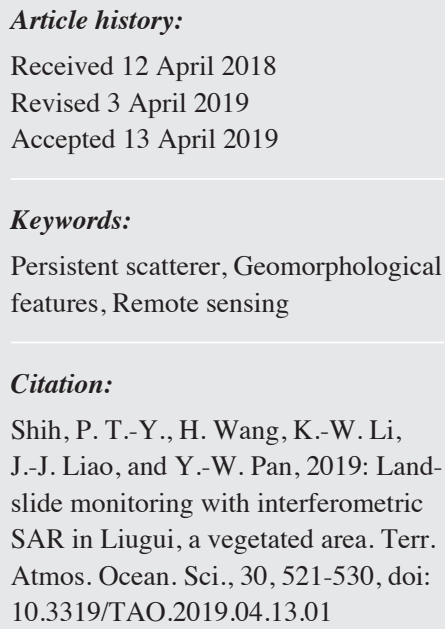

\begin{abstract}
Interferometric SAR analysis with a time series of images obtained from satellite has been proven to be a useful monitoring scheme for geomorphological changes, particularly related to the vertical dimension. The success of this technique relies on the coherence between the images. This imposes severe challenges for applications in vegetated areas. In this study, the landslide process of a site located in Liugui, southern Taiwan, is investigated by a time series of SAR images collected from ALOS PALSAR and Sentinel 1A. This landslide monitoring site is heavily vegetated. From the Persistent Scattering (PS) analysis, ALOS PALSAR presented more extracted points. The wavelength of the band may be a decisive factor. The time series of ALOS images spans across the deadliest typhoon impacted Taiwan in recorded history, Typhoon Morakot on 8 August 2009. It is clear that there are more PS points extracted from the time series after the event as compared to before Typhoon Morakot. This is largely explained by the increase in the amount of bare earth after the disaster. From the interferometric SAR analysis, the development of headward erosion could be observed. Although the number of PS points is limited, the understanding of erosion and landslide progress in the area could still be improved while integrating with the digital elevation model collected with airborne lidar, historic aerial photos, and images collected with UAS (Unmanned Aviation Systems). Together with the in situ measurements, the colluvium depth ranges from $2-40 \mathrm{~m}$ in the area. The surface instability is expected to persist.
\end{abstract}

\section{INTRODUCTION}

SAR (Synthetic Aperture Radar) is a useful earth observation tool, particularly for areas with frequent cloud coverage. Utilizing time series of satellite SAR images for interferometric analysis, information on both the geomorphological feature and its changes could be obtained.Zebker and Goldstein (1986) and Madsen et al. (1993) documented the application of interferometric SAR for topographic mapping. Massonnet et al. (1993) and Zebker et al. (1994) reported the measurements of displacement fields or terrain motions. Inferometric SAR process is capable of providing three-dimensional information. However, the success relies on the coherence between images. Chang et al. (2004) reviewed five applications in Taiwan, namely the coseismic deformation of the Chi-Chi earthquake, uplift of the Tainan area, active deformation of the Hukuo area, rapid land-subsidence in the Chungli area, and seasonal-varied land sub-

\footnotetext{
* Corresponding author

E-mail:tyshih@mail.nctu.edu.tw
}

sidence in the Pingtung area. Hsieh and Shih (2006) studied the first subject, and Hsieh et al. (2011) addressed the issue of the last subject. The Longitudinal Valley Fault (LVF) in eastern Taiwan is the most active tectonic feature of the Taiwan orogen. Yen et al. (2011) studied active deformation of the northern longitudinal valley near the city of Hualien with interferometric SAR. Deffontaines et al. (2017) analysed the Pingting Terraces part of LVF with both PS InSAR and UAV photogrammetry. Utilizing the same surveying technique, Deffontaines et al. (2018) studied onshore Hengchun Fault. Huang et al. (2016a) reviewed the fifteen years of surface deformation in Western Taiwan with insight from SAR interferometry. Su et al. (2018) utilized InSAR, GPS, and levelling for studying the subsidence in Ilan Plain, a transition zone between oblique collision (between the Luzon Arc and the Eurasian Plate) and back-arc extension (the Okinawa Trough). For other types of phenomena, Lee (2014) detected precursor volcanic activity at Baekdusan volcano, located on the border between China and North 
Korea, using multi-interferogram InSAR processing. Du et al. (2017) observed the landslide movement in Tsaoling, a site featured with frequent and massive landslides in Taiwan, with X-band SAR images. There exist many more research studies that utilize interferometric SAR, which are based on the condition that persistent scatterers could be located. However, what would be the situation for heavily vegetated areas? Questions still surround the role of interferometric SAR in landslide monitoring for these areas that are difficult to map. In this study, SAR images from ALOS and Sentinel 1A are collected and processed with the Persistent Scatterer (PS) approach for geomorphological change analysis.

\section{THE SITE}

The study site is located in Liugui, Kaohsiung county, southern Taiwan. From a geomorphological view, the terrain is a spoon shaped side slope covering a 2.28 square $\mathrm{km}$ area, facing northwest, with an average slope of 30 degrees. The foot of this slope is the Laonong river. As shown in Fig. 1, an active fault, Tulungwan fault, passes through the western part of the study site. Tulungwan fault is the north segment of the Chaochou fault, which is classified as the Category II active fault according to Active Fault Map of Taiwan version 2012 (Lin et al. 2012). The distance between the study site and the fault is about $1.4 \mathrm{~km}$. This is a Category 2 active fault according to the official classification of Taiwan. That is, Type 2 active faults have been active in the past 100000 to 10000 years and may be reactivated in the future. Geologically, the underlying rocks, which was formed during the Middle Miocene epoch, belongs to the Chaochow formation. Besides the erosion channels and landslides, most of this site is covered with vegetation, as shown in Fig. 2. The backdrop in Fig. 2 is an orthophoto generated from aerial photo taken on 23 February 2014 with a Zeiss DMC camera at flying height $4000 \mathrm{~m}$ above sea level at $0.317 \mathrm{~m} \mathrm{GSD}$. The outcrop rock founded in this area is the Miocene argillite with thin layers of meta-sandstone. The average attitudes for bedding planes and cleavage measured along the central gully are $\mathrm{N} 40^{\circ} \mathrm{E} / 60^{\circ} \mathrm{S}$ and $\mathrm{N} 28^{\circ} \mathrm{E} / 76^{\circ} \mathrm{S}$, respectively. Some flexural topplings, which are caused by gravitational slope deformation, are observed at the gully slopes. An example of the toppling is shown in Fig. 3. The strata observed at the river bank of the Laonong river are overturned clearly. The colluvium thickness overlain on the rock bed ranges from 2 - $40 \mathrm{~m}$ in the study area. Thin colluvial deposits were observed at the middle and upper parts of the slope and thick colluvial deposits were found at the toe of the slope, respectively. In Fig. 2, the depth is about $2 \mathrm{~m}$ at locations 2, 3, 4, 5, 6. Figure 4 shows the detail of location 1 in Fig. 2, where the depth of colluvial deposit is about $35 \mathrm{~m}$. Figure 5 was taken during a site reconnaissance after the visit of typhoon Megi (27 September to 28 September 2016). The chan- nel bed is full of eroded materials that washed down from higher land. The geomorphic features, including the erosion channel, landslide cliff, were identified with photo interpretation in the stereoscopic viewing environment, as shown in Fig. 6. Historic aerial photos dated 1982, 1988, 1992, 1996, $2007,2013,2014$, and 2015 were used to understand the erosion progress. While comparing 1982 and 2015 photos provide the longest period, 2005 and 2013 photos are acquired closer to the SAR image collection date. Due to the low temporal repetition rate, only long-term erosion process could be observed. Two UAS (Unmanned Aviation System) missions were performed on 21 May 2018 and 22 October 2018 respectively. The flight height is $120 \mathrm{~m}$ above ground with DJI Phantom 4 Pro. 639 photos / 9 GCPs in the first mission and 617 photos / 12 GCPs in the second were used for the triangulation and subsequently generating DSM and orthophoto. The spatial resolution of the orthophoto and DSM from UAS is $0.05 \mathrm{~m}$. These materials are also used in the geological feature interpretation.

\section{THE METHOD AND DATA}

Interferometric SAR analysis has been well developed and applied widely as stated in the introduction. Literature documenting this technique in book format include Hanssen (2001), Kampes (2006), and Ketelaar (2009). Recently published comprehensive review articles include Crosetto et al. (2016), Osmanoğlu et al. (2016), and Pepe and Calò (2017). The fundamental principle of differential interferometric SAR is that SAR image records both the amplitude and the phase of each pixel. As explained by Crosetto et al. (2016), for a ground point $\mathrm{P}$ observed from satellite sensor at position $\mathrm{M}$, the phase measured is $\varphi_{M}$, then,

$\varphi_{M}=\varphi_{\text {geom }-M}+\varphi_{\text {scatt }-M}=\frac{4 \pi D_{M P}}{\lambda}+\varphi_{\text {scatt }-M}$

$D_{M P}$ is the distance between the sensor and the ground point, $\varphi_{\text {geom-M }}$ is the phase shift of microwave resulting from the distance, $\lambda$ is the microwave wavelength, the factor $4 \pi$ is for the flying distance of the microwave, $\varphi_{\text {scatt }-M}$ is the phase shift generated during the interaction of microwaves and ground point. For satellite sensor at position $S$, then,

$\varphi_{S}=\varphi_{\text {geom }-S}+\varphi_{\text {scatt }-S}=\frac{4 \pi D_{S P}}{\lambda}+\varphi_{\text {scatt }-S}$

The interferometric SAR is based on the phase difference,

$\Delta \varphi_{\mathrm{int}}=\varphi_{S}-\varphi_{M}=\frac{4 \pi\left(D_{S P}-D_{M P}\right)}{\lambda}+\varphi_{\text {scatt }-S}-\varphi_{\text {scatt }-M}$

The differential InSAR is used to access the phase shift 


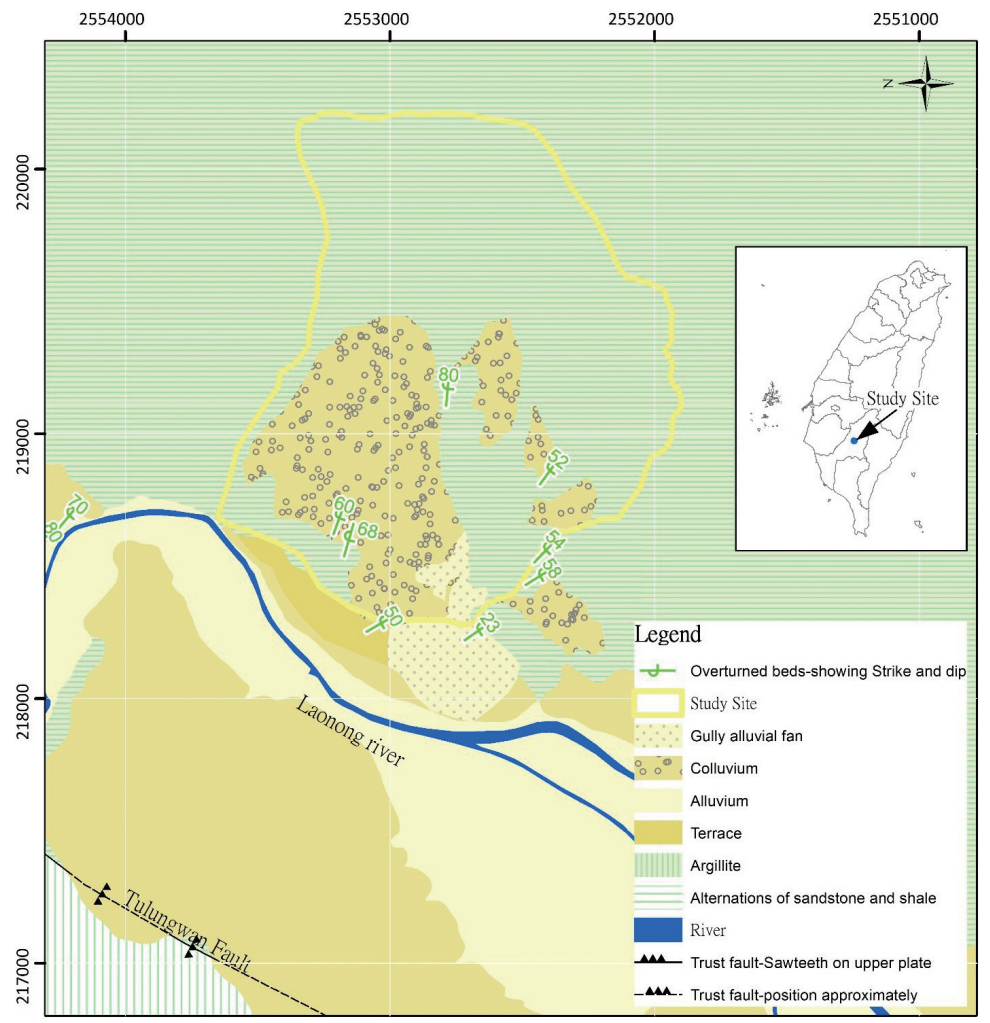

Fig. 1. The geological map of the study site.

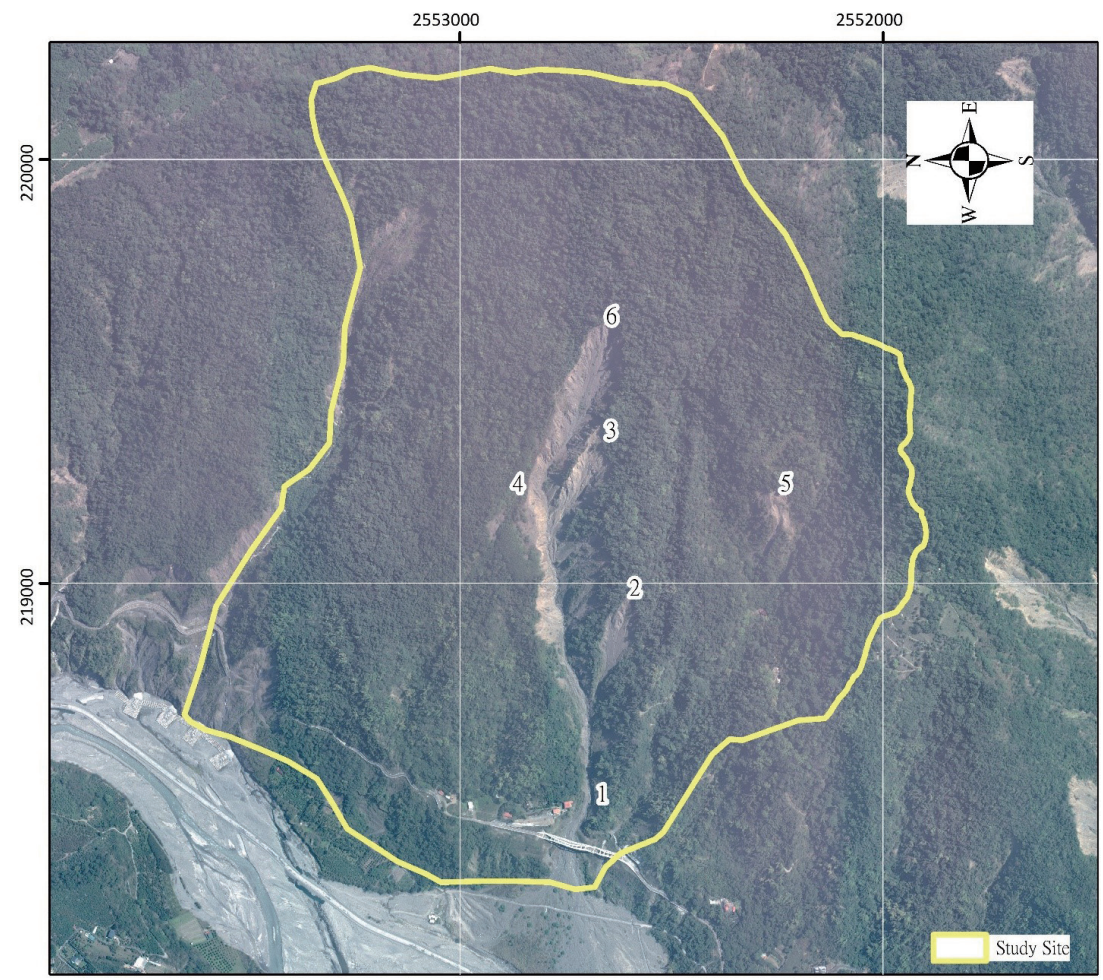

Fig. 2. The orthophoto of the Study site on 23 February 2014. 


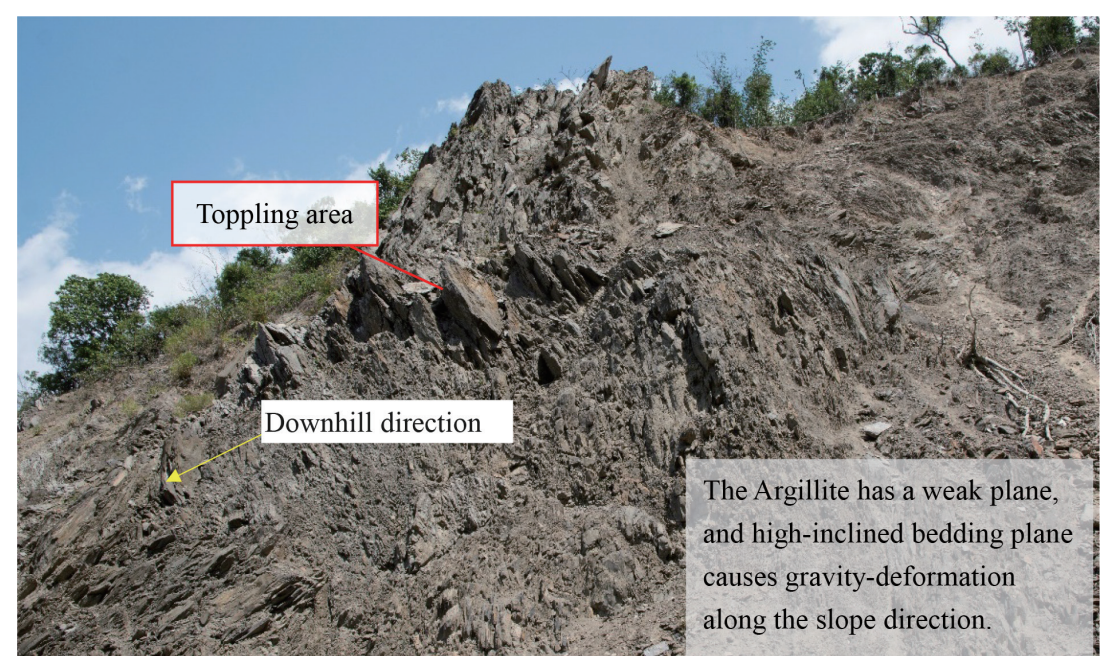

Fig. 3. An example of toppling area at the gully slope.

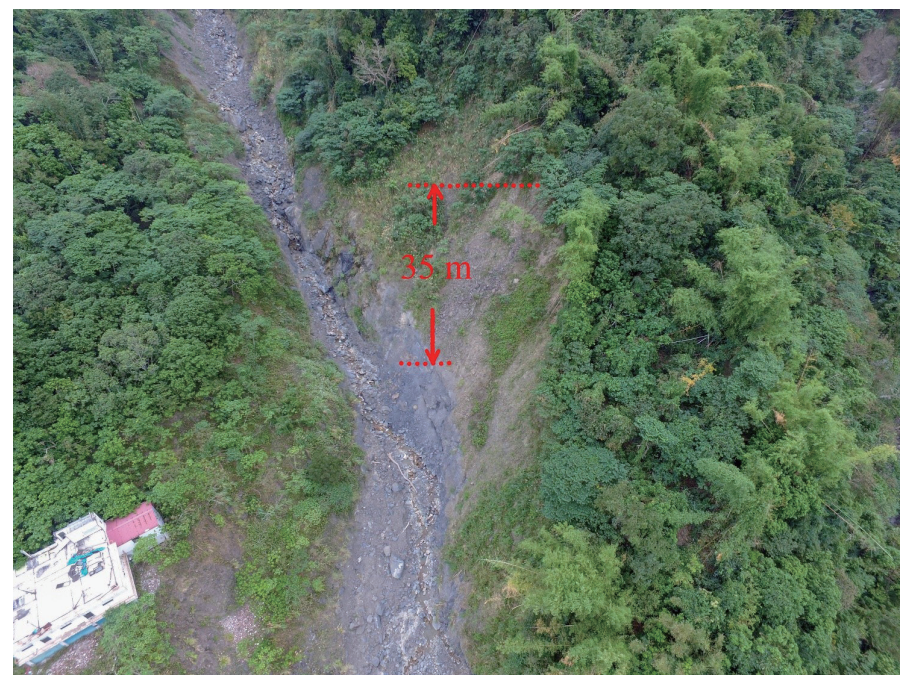

Fig. 4. The thick colluvial deposit observed at the toe of the slope at location 1.

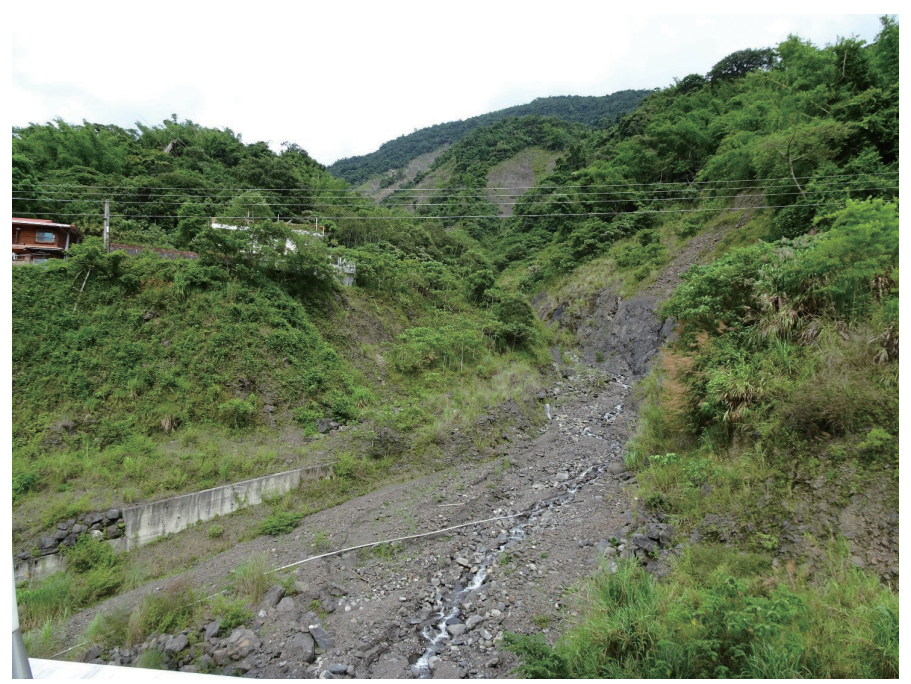

Fig. 5. The eroded material at the downstream of the erosion channel. 


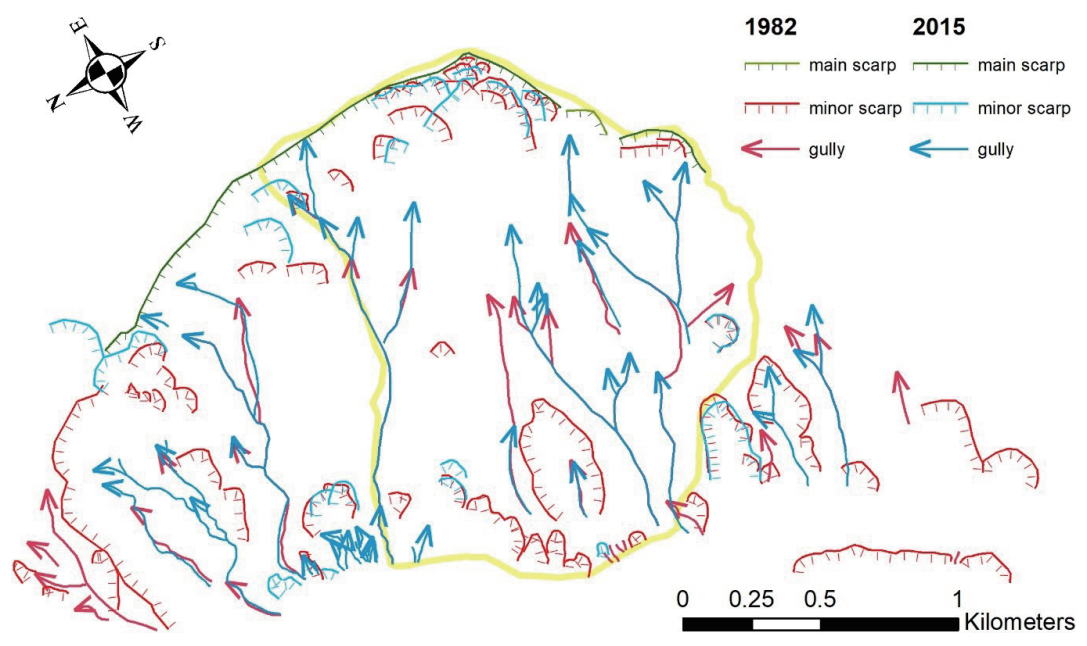

Fig. 6. Geomorphological features identified with historic aerial photos.

caused by ground displacement. There are a number of algorithms and schemes for this analysis, as reviewed in Crosetto et al. (2016), Osmanoğlu et al. (2016), Pepe and Calò (2017), and other literature. In this study, the Stanford Method for Persistent Scatterers (StaMPS) (Hooper et al. 2004; Hooper 2008) is applied.

Regarding the satellite SAR images, 18 scene ALOS PALSAR scenes with $\mathrm{HH}$ polarization, and 15 scenes of Sentinel 1a with VV polarization were used. The selection of images is based on the data availability of the site to the authors. ALOS was operated by JAXA (Japan Aerospace Exploration Agency). Launched on 24 January 2006, started imaging on 16 February 2006, and decommissioned on 12 May 2011. It is a Sun-Synchronous satellite and the recurrent period is approximately 46 days. The altitude is approximately $700 \mathrm{~km}$ with inclination about 98.16 degrees. PALSAR is an L band instrument with wavelength about $23.5 \mathrm{~cm}$, with Fine, ScanSAR, Polarimetric modes. For the Fine Beam Single (FBS) mode, HH or HV, spatial resolution is $7-44 \mathrm{~m}$. For the Fine Beam Dual (FBD) mode, $\mathrm{HH}+\mathrm{HV}$ or $\mathrm{VV}+\mathrm{VH}$, resolution is $14-88 \mathrm{~m}$; swath width, $40-70 \mathrm{~km}$. For the study site, ALOS provides legacy type information. The track-frame is 446 - 450, and the ascending, average incident angle is 34.3 degree. Spatial resolution (Azimuth*Range) is $10 \times 7 \mathrm{~m}$. Images with fine mode and process level L1.1 were used. The 18 scenes as shown in Table 1 is grouped into two disparate groups, separated by 8 August 2009, the date of Typhoon Morakot.

Sentinel 1A is operated by ESA (European Space Agency), a part of the Copernicus program. It was launched on 3 April 2014 at an altitude of approximately $693 \mathrm{~km}$, an inclination angle of about 98.1 degrees, and a revisit period of 12 days. The SAR instrument utilizes $C$ band, wavelength about $6.5 \mathrm{~cm}$. Several imaging modes, Stripmap mode, Interferometric Wide Swath mode, Extra Wide Swath mode and Wave mode, are used. Polarization could be HH or VV;
$\mathrm{HH}+\mathrm{HV}$ or $\mathrm{VV}+\mathrm{VH}$. The incident angle is between 29.1 to 46.0 degrees. The swath width is $250 \mathrm{~km}$. The scenes selected for this study are IW_SLC mode, beam in IW1, VV polarization, incident angle 32.9 degrees. The spatial resolution (Azimuth*Range) is $2.7 \times 14.1 \mathrm{~m}$. As listed in Table 2, it is about one scene every two months. Two events occurred during that period of time: the Meinong Earthquake on 6 February 2016 and Typhoon Megi from 27 September to 28 September 2016. There is one additional scene, 29 September 2016, included.

The ALOS PALSAR images are pre-processed with Doris 4.06 (https://launchpad.net/ubuntu/+source/doris); while Sentinel 1A images are pre-processed with ESA SNAP 6.0 (http://step.esa.int/main/snap-6-0-released/).

\section{RESULTS}

The ALOS images are grouped into two, separated by the event of Typhoon Morakot. These two groups consist of 9 scenes from 18 August 2007 to 8 July 2009, and 9 scenes from 23 August 2009 to 26 February 2011. Sentinel 1A images used ranges from 16 December 2015 to 5 December 2017. From both the PS and SBAS (Small BAseline Subset) approaches, many more points were extracted from ALOS images than from Sentinel ones. In the $2.28 \mathrm{~km}^{2}$ area of the study site, there are 38 PS points from ALOS before Typhoon Morakot (Fig. 7a), 208 points from ALOS after Typhoon Morakot (Fig. 7b), and 16 points from Sentinel 1A after Typhoon Morakot (Fig. 7c).

Before Typhoon Morakot, the change rate within the study site is less than $30 \mathrm{~mm} \mathrm{yr}^{-1}$ from interferometric SAR analysis. Some points with $30-60 \mathrm{~mm} \mathrm{yr}^{-1}$ change rate are located in the central west portion of the site. The point density is largely increased after Typhoon Morakot, as evidenced from the photographs/data. The information carried with interferometric SAR revealed well with the 
topography. Figure 8 uses shaded relief of Digital Elevation Model (DEM) produced with airborne LiDAR survey conducted by CGS (Central Geological Survey) with $1 \mathrm{~m}$ spatial resolution in 2010. The headward erosions along the channels are shown with the subsidence identified along the ridgeline, some larger than $60 \mathrm{~mm} \mathrm{yr}^{-1}$. Although this is line-of-sight (LOS) change rate, it is sufficient to explain the phenomena.

Meanwhile, there are no significant point density changes caused by Meinong Earthquake and Typhoon Megi. The local magnitude $\mathrm{M}_{\mathrm{L}}$ of 2016 Meinong earthquake is 6.4 on the Richter scale. The seismic intensity at Liugui is scale 5 according to the Central Weather Bureau Seismic Intensity Scale, with acceleration between 80 - 250 gal. Typhoon Megi was of moderate intensity at the time it passed through Taiwan. The accumulated rainfall was $770 \mathrm{~mm}$ as recorded at YuYouShan station in Kaohsiung, a weather station $9.94 \mathrm{~km}$ south of Liugui. The accumulated rainfall was $2903 \mathrm{~mm}$ recorded at the same station during the 2009 Typhoon Morakot, an extreme event. Verifying from satellite images, both typhoon Megi and 2016 Meinong earthquake did not increase landslides in the study site significantly. This explains that there is no noticeable change of PS point density.

\section{DISCUSSION}

Based on the experiment conducted, the density of PS points is less than 20 pts per square $\mathrm{km}$ for the study site, a highly vegetated area, with $\mathrm{L}$ band prior to Typhoon Morakot and $\mathrm{C}$ bands. Among the two, in the same vegetated area, $\mathrm{L}$ band has more PS points than $\mathrm{C}$ band. The low density of PS points is likely to be the limitation of interferometric SAR process in a heavily vegetated area. After typhoons or earthquakes, the increased bare earth area could generate more PS points. This also provides evidence of the restriction to this methodology from vegetation. While there are a number of differences between Sentinel 1A and ALOS PALSAR, the most notable difference would be that a CSAR instrument is on-board Sentinel 1A and PALSAR is an
L-band instrument. The central frequencies are $5.405 \mathrm{GHz}$ (corresponding to a wavelength of $\sim 5.5465763 \mathrm{~cm}$ ) and $1.27 \mathrm{GHz}$ (corresponding to $\sim 23.6 \mathrm{~cm}$ ). This finding agrees with Wei and Sandwell (2010) which compared C band and L band in California, and also Jebur et al. (2014) which also applied ALOS PALSAR for landslide monitoring in Gunung pass landslide, Malaysia. While there are a number of studies reporting success in utilizing interferometric SAR for landslide monitoring, even with $\mathrm{X}$ band SAR such as COSMO-SkyMed (Bayer et al. 2017), TerraSAR-X (Du et al. 2017), one should be aware of the reality that the success of interferometric SAR is based on good coherence which is a severe challenge in vegetated areas. The other challenge for landslide monitoring is the fast changing topography. Once the topography is changed, persistent scatterers will be lost. In order to accumulate sufficient time series of SAR images, higher time resolution of the satellite SAR images would be required.

From the interferometric SAR analysis, headward erosion in progress is observed. While cross-validated with the DSM produced from two UAS missions performed on 21 May 2018 and 22 October 2018 respectively, there are $20-60 \mathrm{~mm} \mathrm{yr}^{-1}$ downward displacement in the area nearby erosion channel. Therefore, the vertical displacements observed from InSAR generally agree with those observed with UAS. However, there may be different interpretations. One is the headward erosion. The other would be the sliding or collapse of the sidewall of the erosion channel occurred below the surface, which could be viewed as the latent deformation of the headward erosion process.

In order to validate the findings from InSAR, not just historic aerial photos and those collected with UAS, but also on-site ground measurements. There are six borehole inclinometers deployed in the low part of the slope of this site. Four of these six have been operated since 13 July 2017 to date. There are no clear failure planes and lateral displacements identified from the measurements by 23 October 2018. Considering the upper and middle part of the slope is composed of thin layer of colluvium; while the low part

Table 1. ALOS PALSAR images.

\begin{tabular}{c|c|c|c}
\hline No. & Date & No. & Date \\
\hline 1 & $2007-08-18$ & 10 & $2009-08-23$ \\
2 & $2007-10-03$ & 11 & $2009-10-08$ \\
3 & $2008-01-03$ & 12 & $2010-01-08$ \\
4 & $2008-05-20$ & 13 & $2010-02-23$ \\
5 & $2008-07-05$ & 14 & $2010-07-11$ \\
6 & $2008-08-20$ & 15 & $2010-08-26$ (Master) \\
7 & $2008-10-05$ & 16 & $2010-10-11$ \\
8 & $2009-01-05$ (Master) & 17 & $2010-11-26$ \\
9 & $2009-07-08$ & 18 & $2011-02-26$ \\
\hline
\end{tabular}

Table 2. Sentinel 1A images.

\begin{tabular}{c|c|c|c}
\hline No. & Date & No. & Date \\
\hline 1 & $2015-12-16$ & 9 & $2016-12-10$ \\
2 & $2016-02-02$ (Master) & 10 & $2017-02-08$ \\
3 & $2016-02-14$ & 11 & $2017-04-09$ \\
4 & $2016-04-14$ & 12 & $2017-06-08$ \\
5 & $2016-06-01$ & 13 & $2017-08-07$ \\
6 & $2016-08-12$ & 14 & $2017-10-06$ \\
7 & $2016-09-29$ & 15 & $2017-12-05$ \\
8 & $2016-10-11$ & & \\
\hline
\end{tabular}


(a)

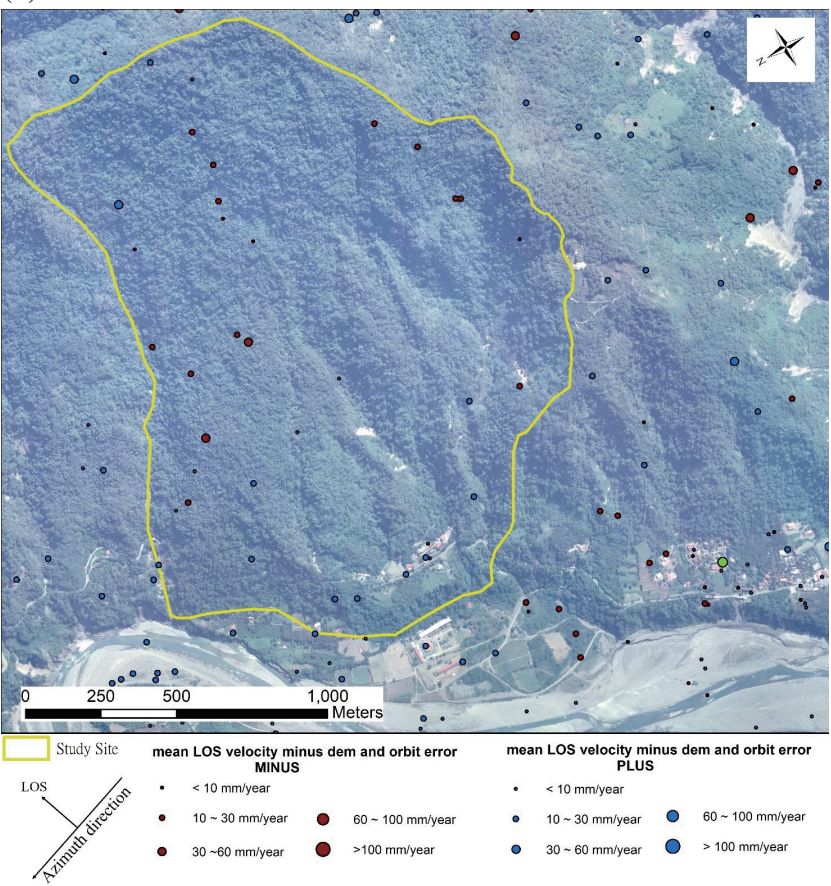

(b)

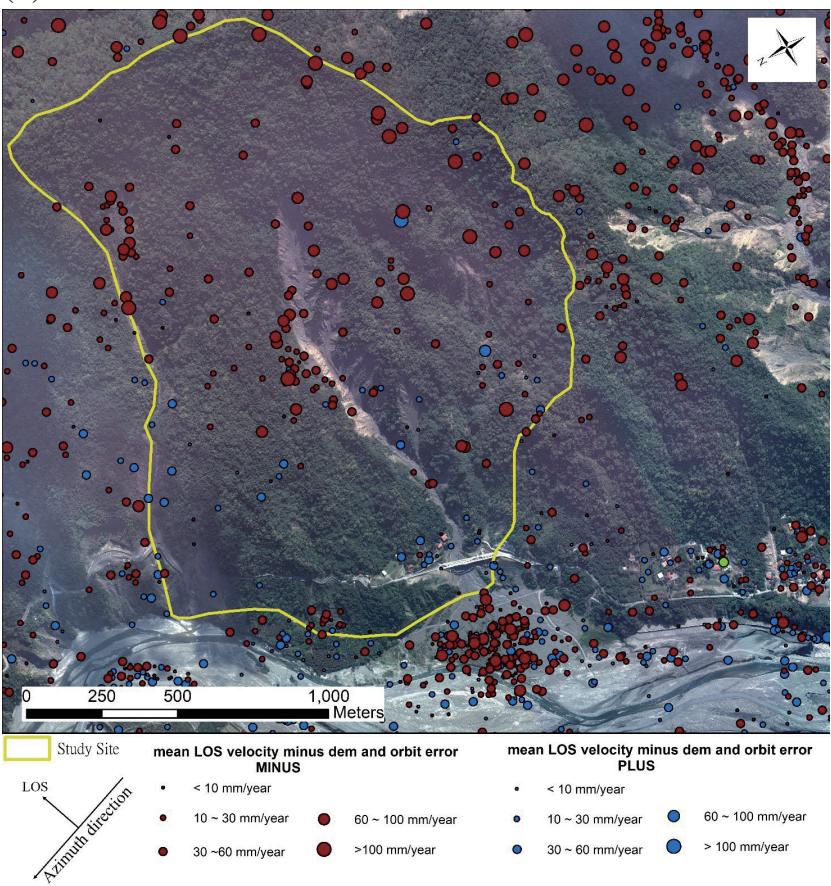

(c)

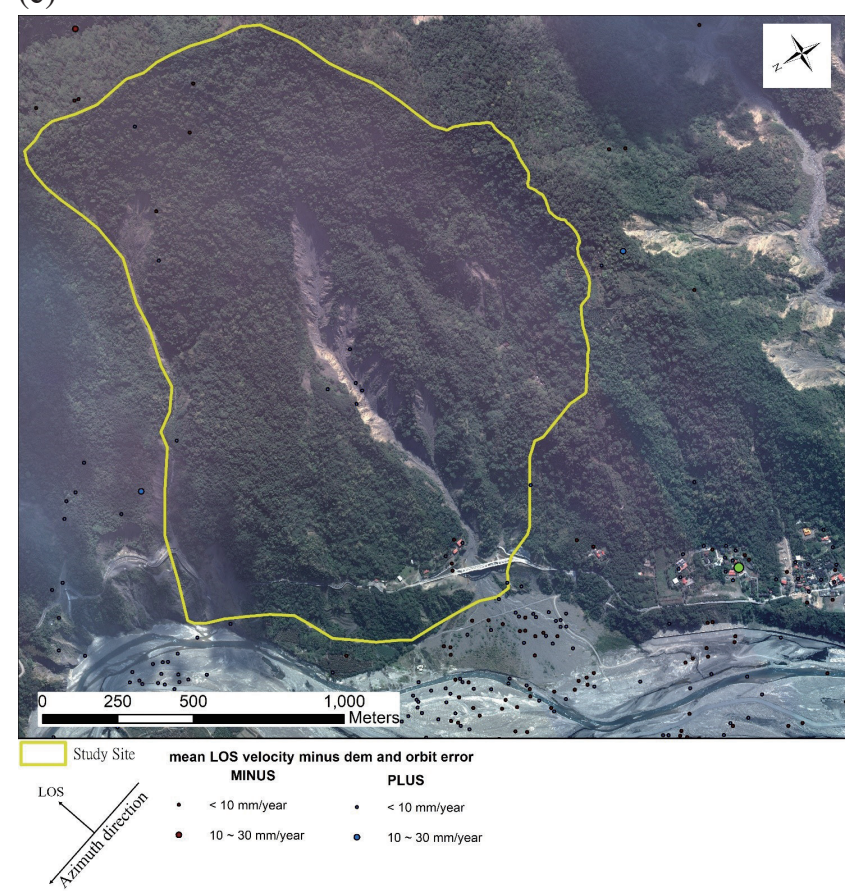

Fig. 7. (a) PS points derived from ALOS before Typhoon Morakot (2007 - 2009). (b) PS points derived from ALOS after Typhoon Morakot (2009 - 2011). (c) PS points derived from Sentinel 1A after Typhoon Morakot (2015 - 2017). 


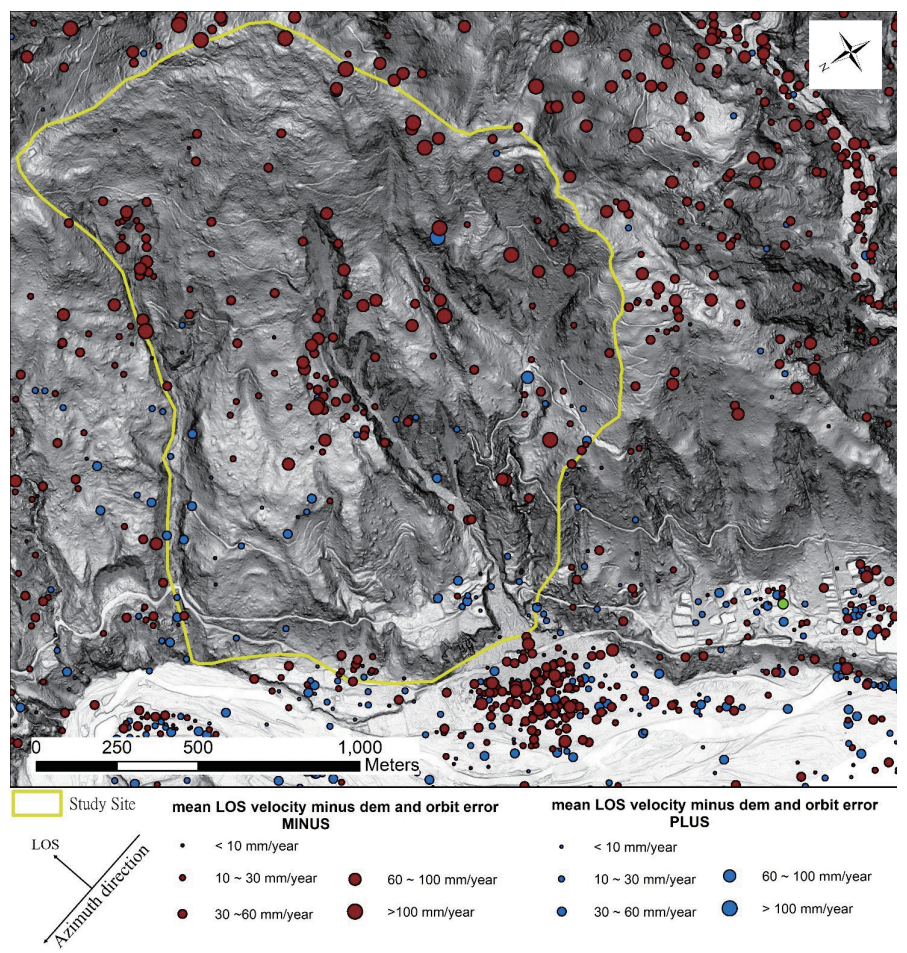

Fig. 8. PS points derived from ALOS after Typhoon Morakot with slope map as backdrop.

has deep layer, it is justified that no significant lateral displacements observed in the low part. In the same site, five continuous GNSS monitoring stations, equipped with single frequency receiver, were deployed. The location of these stations is shown in Fig. 9. From the data collected during October 2014 to October 2015, and September 2017 to August 2018, LG015-G6 has larger horizontal shifts; while the magnitude of movement on other stations are all less than $3 \mathrm{~cm}$.

As shown in Fig. 9, LG015-G6 is located on the roadside of Highway Kao-133. On this very place, a road obstruction due to landslide were recorded in 2013. This place is identified as the crown of a local landslide. Between April and October of 2015, $40 \mathrm{~mm}$ northward, $30 \mathrm{~mm}$ westward displacement is observed. $40 \mathrm{~mm}$ northward, $50 \mathrm{~mm}$ westward for the period between January and August of 2018 . The direction of displacements are consistent. LG015-G6 is considered to be capable of observing the local (crown) displacement-change rate at the slope crown. LG015-G2 is located in the crown of the main landslide, and also the head of the erosion channel. Between January and October of 2018, no horizontal movement observed; while $60 \mathrm{~mm}$ downward displacement is found. Regarding the vertical direction, all five GNSS stations shown downward displacement, in the range of $10-50 \mathrm{~mm}$.

\section{CONCLUSION}

Although the possibility of monitoring landslides in vegetated area solely with interferometric SAR has been proven to be wishful thinking, potentially useful information could still be provided when condition is favorable. This study observed that there is headward erosion in progress shown from the interferometric SAR analysis. The surface of the area is unstable, resulting from the loosely structured colluvium layer. With interferometric SAR alone, there is not sufficient information about the landslide process. Due to the fundamental geometry which measurements are based, lidar has much better penetration capability to the ground than both interferometric SAR and photogrammetry in vegetated area. But, the change rate of PS points from interferometric SAR enriches the observation of the process.

While Multi-Temporal InSAR carries valuable information, it provides neither complete nor solid evidences alone. In order to clarify the issues of deformation pattern and geomorphological features, more and longer observations with multiple instrumentation systems are required along with further in-depth analysis. Among many other subjects, the rate change before and after 2016 Meinong earthquake and Typhoon Magi could be characterized with InSAR time series for finding if the acceleration or deceleration of downslope rate occurred in the period of observation. Lin et al. (2016) addresses the 2010 Jiashian earthquake and Huang et al. (2016b) discussed 2016 Meinong Earthquake from the regional and fault system point of view. While the current study is site based, the role of surface deformation resulting from larger scale factors may also be a subject. 


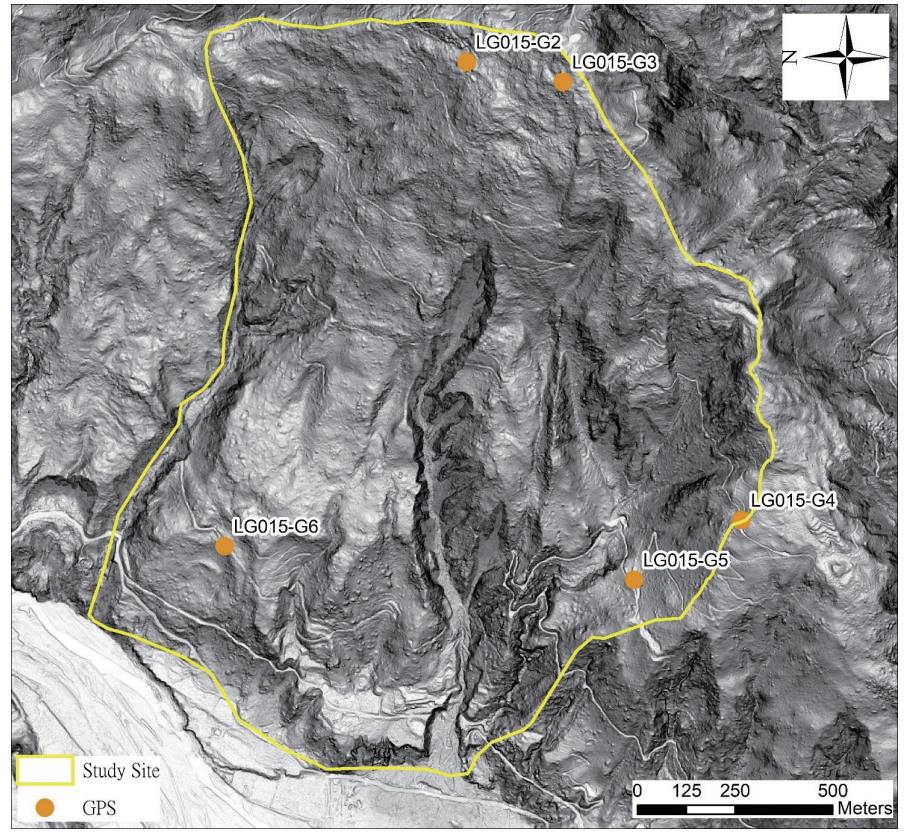

Fig. 9. The location of GPS monitoring stations at the site.

Regarding InSAR technique itself, coherence loss due to vegetation is a severe limitation, as shown in this study that PS density is low. Because the coherence loss due to vegetation is more severe to $\mathrm{C}$ band than $\mathrm{L}$ band, Sentinel-1, which utilizes $\mathrm{C}$ band, would have difficulties in the vegetated area while works fine with bare-earth. C-band, even $\mathrm{X}$-band images are still useful for landslide monitoring, but with relatively larger limitation to the vegetated cover. PS InSAR has higher requirement to the scatters. That is, the scatters identified should be well defined in all images in the time series. Other processing schemes such as various SBAS implementations and their revisions may be applied for potential improvement.

Acknowledgements The authors are grateful for the support from the Forestry Bureau, Council of Agriculture, Taiwan. In addition to the financial support provided, the understanding of the study site would not be as comprehensive without the information and knowledge shared from the Bureau staff. The first author also wish to thank the Ministry of Science and Technology, Taiwan, to the support for building up the multi-temporal InSAR analysis capacity through MOST 107-2625-M-009-002 research grant. This manuscript benefited from comments from two anonymous reviewers. Their constructive comments led to a significant improvement of the manuscript.

\section{REFERENCES}

Bayer, B., A. Simoni, D. Schmidt, and L. Bertello, 2017: Using advanced InSAR techniques to monitor land- slide deformations induced by tunneling in the Northern Apennines, Italy. Eng. Geol., 226, 20-32, doi: 10.1016/j.enggeo.2017.03.026. [Link]

Chang, C.-P., K.-S. Chen, C.-T. Wang, J.-Y. Yen, T.-Y. Chang, and C.-W. Lin, 2004: Application of spaceborne radar interferometry on crustal deformations in Taiwan: A perspective from the nature of events. Terr. Atmos. Ocean. Sci., 15, 523-543, doi: 10.3319/ TAO.2004.15.3.523(EP). [Link]

Crosetto, M., O. Monserrat, M. Cuevas-González, N. Devanthéry, and B. Crippa, 2016: Persistent scatterer interferometry: A review. ISPRS J. Photogram. Rem. Sens., 115,78-89, doi: 10.1016/j.isprsjprs.2015.10.011. [Link]

Deffontaines, B., K.-J. Chang, J. Champenois, B. Fruneau, E. Pathier, J.-C. Hu, S.-T. Lu, and Y.-C. Liu, 2017: Active interseismic shallow deformation of the Pingting terraces (Longitudinal Valley - Eastern Taiwan) from UAV high-resolution topographic data combined with InSAR time series. Geomatics, Natural Hazards and Risk, 8, 120-136, doi: 10.1080/19475705.2016.1181678. [Link]

Deffontaines, B., K.-J. Chang, J. Champenois, K.-C. Lin, C.T. Lee, R.-F. Chen, J.-C. Hu, and S. Magalhaes, 2018: Active tectonics of the onshore Hengchun Fault using UAS DSM combined with ALOS PS-InSAR time series (Southern Taiwan). Nat. Hazards Earth Syst. Sci., 18, 829-845, doi: 10.5194/nhess-18-829-2018. [Link]

Du, Y., Q. Xu, L. Zhang, G. Feng, Z. Li, R.-F. Chen, and C.-W. Lin, 2017: Recent Landslide Movement in Tsaoling, Taiwan Tracked by TerraSAR-X/TanDEM-X 
DEM Time Series. Remote Sens., 9, 353, doi: 10.3390/ rs9040353. [Link]

Hanssen, R. F., 2001: Radar Interferometry: Data Interpretation and Error Analysis, Springer, Dordrecht, 318 pp, doi: 10.1007/0-306-47633-9. [Link]

Hooper, A., 2008: A multi-temporal InSAR method incorporating both persistent scatterer and small baseline approaches. Geophys. Res. Lett., 35, doi: 10.1029/2008GL034654. [Link]

Hooper, A., H. Zebker, P. Segall, and B. Kampes, 2004: A new method for measuring deformation on volcanoes and other natural terrains using InSAR persistent scatterers. Geophys. Res. Lett., 31, doi: 10.1029/2004GL021737. [Link]

Hsieh, C.-S. and T.-Y. Shih, 2006: Coseismic deformation of Chi-Chi earthquake as detected by differential synthetic aperture radar interferometry and GPS data. Terr. Atmos. Ocean. Sci., 17, 517-532, doi: 10.3319/ TAO.2006.17.3.517(T). [Link]

Hsieh, C.-S., T.-Y. Shih, J.-C. Hu, H. Tung, M.-H. Huang, and J. Angelier, 2011: Using differential SAR interferometry to map land subsidence: A case study in the Pingtung plain of SW Taiwan. Nat. Hazards, 58, 13111332, doi: 10.1007/s1 1069-011-9734-7. [Link]

Huang, M.-H., R. Bürgmann, and J.-C. Hu, 2016a: Fifteen years of surface deformation in Western Taiwan: Insight from SAR interferometry. Tectonophysics, 692, 252-264, doi: 10.1016/j.tecto.2016.02.021. [Link]

Huang, M.-H., H. Tung, E. J. Fielding, H.-H. Huang, C. Liang, C. Huang, and J.-C. Hu, 2016b: Multiple fault slip triggered above the $2016 M_{w} 6.4$ MeiNong earthquake in Taiwan. Geophys. Res. Lett., 43, 7459-7467, doi: 10.1002/2016GL069351. [Link]

Jebur, M. N., B. Pradhan, and M. S. Tehrany, 2014: Detection of vertical slope movement in highly vegetated tropical area of Gunung pass landslide, Malaysia, using L-band InSAR technique. Geosci. J., 18, 61-68, doi: 10.1007/s12303-013-0053-8. [Link]

Kampes, B. M., 2006: Radar Interferometry: Persistent Scatterer Technique, Springer, Dordrecht, The Netherlands, 221 pp, doi: 10.1007/978-1-4020-4723-7. [Link]

Ketelaar, V. B. H., 2009: Satellite Radar Interferometry: Subsidence Monitoring Techniques, Springer, Dordrecht, 252 pp, doi: 10.1007/978-1-4020-9428-6. [Link]

Lee, C.-W., 2014: Baekdusan volcano time-series analysis from 1992 to 1998 using multi-interferogram InSAR processing. Terr. Atmos. Ocean. Sci., 25, 743-754, doi: 10.3319/TAO.2014.06.06.01(T). [Link]

Lin, C.-W., S.-T. Lu, and W.-S. Chen, 2012: Active Fault Map of Taiwan, Version 2012, Central Geological Survey, Taiwan.
Lin, K.-C., B. Delouis, J.-C. Hu, J.-M. Nocquet, and L. Mozziconacci, 2016: Reassessing the complexity of the rupture of the $2010 \mathrm{Jia}-$ Shian earthquake (Mw 6.2) in Southwestern Taiwan by inverting jointly teleseismic, strong-motion and CGPS data. Tectonophysics, 692, 278-294, doi: 10.1016/j.tecto.2015.09.015. [Link]

Madsen, S. N., H. A. Zebker, and J. Martin, 1993: Topographic mapping using radar interferometry: Processing techniques. IEEE Trans. Geosci. Remote Sensing, 31, 246-256, doi: 10.1109/36.210464. [Link]

Massonnet, D., M. Rossi, C. Carmona, F. Adragna, G. Peltzer, K. Feigl, and T. Rabaute, 1993: The displacement field of the Landers earthquake mapped by radar interferometry. Nature, 364, 138-142, doi: 10.1038/364138a0. [Link]

Osmanoğlu, B., F. Sunar, S. Wdowinski, and E. Cabral-Cano, 2016: Time series analysis of InSAR data: Methods and trends. ISPRS J. Photogram. Rem. Sens., 115, 90102, doi: 10.1016/j.isprsjprs.2015.10.003. [Link]

Pepe, A. and F. Calò, 2017: A review of interferometric synthetic aperture RADAR (InSAR) multi-track approaches for the retrieval of earth's surface displacements. Appl. Sci., 7, 1264, doi: 10.3390/app7121264. [Link]

Su, Z., J.-C. Hu, E. Wang, Y. Li, Y. Yang, and P.-L. Wang, 2018: Monitoring interseismic activity on the Ilan Plain (NE Taiwan) using Small Baseline PS-InSAR, GPS and leveling measurements: Partitioning from arc-continent collision and backarc extension. Geophys. J. Int., 212, 264-283, doi: 10.1093/gji/ggx394. [Link]

Wei, M. and D. T. Sandwell, 2010: Decorrelation of L-band and C-band interferometry over vegetated areas in California. IEEE Trans. Geosci. Remote Sensing, $\mathbf{4 8}$, 2942-2952, doi: 10.1109/TGRS.2010.2043442. [Link]

Yen, J.-Y., C.-H. Lu, C.-P. Chang, A. J. Hooper, Y.-H. Chang, W.-T. Liang, T.-Y. Chang, M.-S. Lin, and K.S. Chen, 2011: Investigating active deformation in the Northern Longitudinal valley and city of hualien in eastern Taiwan using persistent scatterer and smallbaseline SAR interferometry. Terr. Atmos. Ocean.Sci., 22, 291-304, doi: 10.3319/TAO.2010.10.25.01(TT). [Link]

Zebker, H. A. and R. M. Goldstein, 1986: Topographic mapping from interferometric synthetic aperture radar observations. J. Geophys. Res., 91, 4993-4999, doi: 10.1029/JB091iB05p04993. [Link]

Zebker, H. A., P. A. Rosen, R. M. Goldstein, A. Gabriel, and C. L. Werner, 1994: On the derivation of coseismic displacement fields using differential radar interferometry: The Landers earthquake. J. Geophys. Res., 99, 19617-19634, doi: 10.1029/94JB01179. [Link] 